\title{
Decisão de preços em economias monetárias e metas de inflação: a difícil conciliação entre crescimento e estabilidade de preços ${ }^{1}$
}

\author{
Gabriel Caldas Montes ${ }^{2}$ \\ Carmem Aparecida Feijó ${ }^{3}$
}

\begin{abstract}
Resumo
Atualmente um número considerável de países adota explicitamente o regime de metas para a inflação como uma referência para a condução da política monetária e como forma de afetar as expectativas do público. A política monetária, sob o regime de metas de inflação, é conduzida fundamentalmente baseada na manipulação de um único instrumento de controle da inflação - a taxa de juros. Contudo, advoga-se que a insistência no uso exclusivo desse instrumento traz consequências negativas para a formação de expectativas sobre o potencial de crescimento da economia. Nesse sentido, o presente trabalho tem como objetivo explicitar o processo de formação de preços em economias de mercado e discutir como a política monetária, sob o regime de metas de inflação, atua de maneira satisfatória sobre a formação de expectativas para a inflação, mas de maneira nociva sobre a formação das expectativas de crescimento do produto a longo prazo.
\end{abstract}

Palavras-chave: Inflação - Metas; Preços - Formação; Desenvolvimento econômico.

\begin{abstract}
Inflation targeting and price-making in monetary economies: is it possible to conciliate growth with price stability?

Recently a number of countries have adopted explicit inflation targets as a guide for policy since a numerical target is attractive for anchoring inflation expectations. Monetary policy, under inflation targeting, is implemented grounded on handling only one instrument to control inflation - the interest rate. Nevertheless, the perseverance on using this kind of rule brings negative consequences for the expectations about potential economic growth. Hence, the paper aims at making evident the process of price-making in market economies and discuss how the monetary policy, under inflation targeting, affects positively the process of inflation expectations formation, however with harmful consequences upon expectations regarding the output growth.
\end{abstract}

Key words: Inflation targeting; Pricing; Economic development. JEL E31, E52, E58, E61.

\section{Introdução}

Desde a década de 1980, quando os principais países industrializados foram bem-sucedidos em reduzir suas taxas de inflação para patamares baixos e

(1) Trabalho recebido em janeiro de 2008 e aprovado em outubro de 2008.

(2) Professor da Faculdade de Economia da Universidade Federal Fluminense (UFF), Niteroi, RJ, Brasil. E-mail:gabrielmontesuff@yahoo.com.br.

(3) Professora da Faculdade de Economia da Universidade Federal Fluminense e pesquisadora do CNPq (Conselho Nacional de Desenvolvimento Científico e Tecnológico), Niteroi, RJ, Brasil. E-mail: cfeijo@terra.com.br.

Economia e Sociedade, Campinas, v. 18, n. 3 (37), p. 469-491, dez. 2009. 
estáveis, policymakers de diferentes nações têm cada vez mais se comprometido explicitamente com o objetivo de manter a inflação sob controle. Embora a estabilidade dos preços não represente uma condição suficiente para um melhor desempenho econômico visto pelo lado real, existe um amplo consenso, contudo, de que a estabilidade inflacionária representa uma condição necessária tanto para o crescimento econômico quanto para o desenvolvimento.

Norteado por hipóteses convencionais, as quais determinam que a estabilidade dos preços deva ser o único e principal objetivo de longo prazo a ser perseguido pelas autoridades monetárias, um "novo consenso" macroeconômico vem estabelecendo novas diretrizes em termos de atuação dos bancos centrais por meio de suas políticas monetárias. Com base nesse "novo consenso" o regime de metas de inflação e a utilização de regras que limitem o discricionarismo dos bancos centrais vêm se fortalecendo, ganhando evidência e novos adeptos. Como Bernanke (2003) mencionou em seu discurso na Annual Washington Policy Conference of the National Association of Business Economists, "one of the more interesting developments in central banking in the past dozen years or so has been the increasingly widespread adoption of the monetary policy framework known as inflation targeting".

Atualmente um número considerável de países adota explicitamente o regime de metas para a inflação como uma referência para a condução da política monetária e como forma de afetar as expectativas do público, dado que uma meta numérica representa uma boa estratégia para ancorar expectativas de inflação, o que, por sua vez, pode proporcionar efeitos favoráveis nos mercados financeiros e consequentemente na economia. O regime é também capaz de reduzir um tipo específico de incerteza que ronda a economia, denominada de incerteza estratégica, ${ }^{4}$ pois requer comprometimento, transparência e accountability dos bancos centrais.

A política monetária, sob o regime de metas de inflação, é conduzida fundamentalmente baseada na manipulação de um único instrumento de controle da inflação - a taxa de juros - sob o argumento de que é necessário persistir em regras fixas, para que a autoridade monetária conquiste reputação, a política ganhe credibilidade e seja transparente, e com isso faça convergir a taxa de inflação para a meta. ${ }^{5}$ Contudo, a insistência no uso exclusivo desse instrumento traz

(4) Para maiores detalhes acerca desse tipo de incerteza e, também, outros tipos de incerteza, ver: Batini, Martin e Salmon (1999); Dequech (1999a, 1999b); ECB (2001); Dow (2004).

(5) Para um estudo comparativo acerca das evidências empíricas sobre o sucesso do regime de metas de inflação, ver Angeriz e Arestis (2006). Nesse artigo os autores levantam a seguinte questão: teria o regime de metas de inflação alguma influência sobre a inflação? O trabalho mostra que os resultados empíricos são controversos. 
consequências negativas para a formação de expectativas sobre o potencial de crescimento da economia. ${ }^{6}$

O presente trabalho tem como objetivo explicitar o processo de formação de preços em economias de mercado e discutir como a política monetária, sob o regime de metas de inflação, atua de maneira satisfatória sobre a formação de expectativas para a inflação, mas de maneira nociva sobre a formação das expectativas de crescimento do produto a longo prazo. A literatura sobre metas de inflação distingue, de acordo com Svensson (1997, 1999), Bernanke et al. (1999) e Mishkin (2007) pelo menos dois tipos de arcabouço institucional para o regime de metas de inflação: um regime de metas mais flexíveis - flexible inflation forecast targeting - e um mais estrito - strict inflation targeting. Ambos os tipos têm em comum a ênfase na manipulação de um único instrumento de política econômica, a taxa de juros, para combater a inflação. Nesse sentido, o regime de metas de inflação, tanto o flexível como o estrito, tende a subutilizar outros instrumentos de política econômica no combate à inflação, que podem ser mais adequados quando se considera explicitamente o processo de formação de preços na economia e quando o objetivo da política monetária privilegie, além da estabilização de preços, a construção de contextos econômicos favoráveis à expansão do produto ao longo do tempo.

Na prática, a adoção de uma política de metas de inflação mais estrita implica maior ônus em termos de estabilização do produto no curto prazo se comparada a uma política mais flexível. A adoção de um regime de metas de inflação mais estrito pode ser justificada na busca de credibilidade da autoridade monetária e de suas políticas. Considerando que a autoridade monetária em países com histórico de inflação alta e persistente têm mais dificuldade em impor uma política monetária crível, a opção por uma política de metas de inflação estrita pode ser uma estratégia a ser seguida. O ponto de destaque neste artigo é mostrar como expectativas que orientam decisões das firmas consideram cenários levando em conta o contexto de política macroeconômica. Na medida em que prevalece uma disciplina monetária mais rígida, maior será o impacto negativo sobre a formação de expectativas sobre o potencial de crescimento da economia ao longo do tempo. Uma disciplina monetária flexível, ainda que possa afetar menos negativamente o produto no curto prazo, pode consolidar um cenário de política macroeconômica que não estimule contextos mais favoráveis à expansão do

(6) Dilema recente da economia brasileira foi e continua sendo como conciliar crescimento com estabilidade de preços. O sucesso do controle da inflação a partir de 1994, depois de anos de convívio com elevadas taxas de crescimento dos preços e vários planos de estabilização malsucedidos, não trouxe o tão esperado ciclo de prosperidade. Verificou-se, entretanto, uma contrapartida negativa ao processo de estabilização da inflação: a estimativa de taxa de crescimento do produto potencial decresceu drasticamente e passou a girar em torno de 3,5\%, acompanhada de taxas de desemprego relativamente elevadas e alta informalidade. 
produto, na medida em que o arcabouço institucional de política econômica desenvolvido não privilegie outros instrumentos de política. ${ }^{7}$

O texto se divide nas seguintes seções: a Seção 2 discute a política monetária sob o regime de metas, a Seção 3 apresenta o processo de formação de preços, segundo a abordagem pós-keynesiana, onde o mark up é entendido como uma variável estratégica para a firma, e, na última seção, são apresentadas as considerações finais acerca do trabalho, destacando que o entendimento do processo de formação de preços pela firma é fundamental para se avaliar a eficácia da política monetária.

\section{Política monetária sob o regime de metas de inflação}

Considerando a influência exercida pelas expectativas de inflação sobre a inflação efetiva e a influência exercida pela política monetária sobre essas expectativas, é possível argumentar em termos práticos a favor da utilização do regime de metas de inflação como forma de manter a inflação sob controle. Seu propósito é disciplinar monetariamente a execução da política monetária, fazendo com que o próprio regime de metas de inflação se traduza em um arcabouço que restrinja (ou amenize) o grau de discricionarismo da política adotada pela autoridade monetária. ${ }^{8}$ Na prática, como aponta Bernanke et al. (1999), todos os regimes de política monetária são discricionários, sendo a discrição apenas uma questão de grau.

O regime possui como dois dos principais atributos a fixação e o anúncio de uma meta quantitativa para a taxa de inflação dos períodos subsequentes, com a finalidade de servir como principal referência para o processo de formação de expectativas para a inflação e como principal guia para a condução da política monetária. É caracterizado pelo anúncio oficial de uma meta pontual para a taxa de inflação ou de um intervalo (banda) para flutuação da taxa de inflação e pelo explícito reconhecimento de que o principal objetivo da política monetária é com a manutenção de uma taxa de inflação baixa e estável. ${ }^{9}$

(7) Para uma referência sobre políticas de combate à inflação de cunho keynesiano, ver Carvalho (1999) e Sicsú (2003).

(8) Como aponta De Mendonça (2001, p. 65), esse regime pode contemplar alguma discricionariedade: "Uma das principais características do regime de metas para a inflação é que essa estrutura não pode ser entendida como um caso de regra rígida. De forma diferente de simples regras políticas, as metas para a inflação permitem ao $\mathrm{BCB}$ o uso de modelos de estrutura e decisão em conjunto com todas as informações relevantes para determinar a ação política mais adequada para obter a meta anunciada. Além disso, há a vantagem de que o regime em consideração possibilita o uso de políticas discricionárias sem levar à perda de credibilidade”.

(9) Segundo Mishkin (2004), o regime de metas de inflação compreende cinco elementos fundamentais: "1) the public announcement of medium-term numerical targets for inflation; 2) an institutional commitment to price stability as the primary goal of monetary policy, to which other goals are subordinated; 3) an information inclusive strategy in which many variables, and not just monetary aggregates or the exchange rate, are used for deciding the setting of policy instruments; 4) increased transparency of the monetary policy strategy through communication with the public and the markets about the plans, objectives, and decisions of the monetary authorities; and 5) increased accountability of the central bank for attaining its inflation objectives". 
Alguns dos benefícios argumentados em favor da adoção do regime de metas de inflação estão relacionados aos seus impactos sobre as expectativas de inflação e aos custos sobre o produto, o emprego e a renda atribuídos às políticas de desinflação. Por esse regime, a autoridade monetária conduz a política monetária de maneira forward-looking, isto é, reagindo fortemente a mudanças nas expectativas de inflação e às pressões inflacionárias. Ou seja, a autoridade monetária busca, constantemente, influenciar as expectativas de inflação formadas pelo público de modo a fazer com que essas sejam levadas em conta e induzam a inflação observada a convergir para a meta predeterminada.

Os que advogam a favor desse regime argumentam que, com a sua adoção, a autoridade monetária irá possuir uma maior capacidade de influenciar as expectativas de inflação desde que atuem por meio de políticas críveis. ${ }^{10}$ Assim, a condução da política monetária deve estar associada à perseguição de um único objetivo, ou seja, atingir a meta de inflação, pois, no longo prazo, produto e emprego encontrar-se-ão em suas taxas naturais. Vale ressaltar que embora a política monetária tenha a meta pontual de inflação como principal objetivo, a estratégia, de fato, mais utilizada para a prática do regime de metas de inflação tem sido o anúncio de uma meta pontual com bandas de tolerância, o que confere certo grau de flexibilidade à política monetária.

No regime de metas de inflação, a autoridade monetária busca manter o controle da inflação por meio, basicamente, de manipulações da taxa básica de juros, não importando muito a origem da pressão inflacionária. A decisão por fixar a taxa básica de juros em um determinado nível é fortemente influenciada pelas expectativas formadas para a inflação e pelo comportamento observado para a trajetória de inflação. Destarte, a autoridade monetária se utiliza do seguinte procedimento: manipula a taxa básica de juros em resposta aos desvios das expectativas de inflação e da própria inflação observada em relação à meta de inflação e, também, em resposta às oscilações no hiato do produto (que se traduzem em pressões inflacionárias), com intuito de fazer convergir tanto a inflação efetiva quanto as expectativas de inflação novamente para a meta.

Acerca das condições que antecedem a implementação de estratégias bemsucedidas de políticas monetárias, como sugerido por Mishkin (2000, 2007), existe um amplo consenso entre economistas e "central bankers" acerca de alguns princípios básicos que devem servir como guias úteis para os bancos centrais conduzirem suas políticas de modo a melhor alcançarem seus objetivos. Esses

(10) Pela ótica do arcabouço teórico que sustenta esse regime, uma política crível é resultado de dois tipos de credibilidade: (i) a operacional, referente à habilidade de o banco central fazer uso da política monetária, de modo a fazer com que a meta de inflação anunciada seja cumprida; e (ii) a política, que reflete o temor dos investidores em relação à probabilidade de o regime monetário mudar, por conseguinte, levando a busca da estabilidade de preços a deixar de ser prioridade para a condução da política monetária. 
princípios são: 1) substanciais benefícios são conseguidos com a estabilidade dos preços; 2) a política fiscal deve ser conduzida de maneira coordenada com a política monetária; 3) o problema de inconsistência temporal deve ser evitado; 4) a política monetária deve ser forward-looking; 5) accountability representa um princípio democrático básico; 6) a política monetária deve preocupar-se tanto com flutuações no produto quanto nos preços; e 7) as reversões de ciclos mais sérias na economia estão associadas às instabilidades (ou mesmo crises) financeiras.

\subsection{Regime de metas de inflação flexível}

Na prática e de forma generalizada, o regime de metas de inflação pode ser descrito como sendo de flexible inflation forecast targeting. Esse tipo de estratégia é caracterizado pela adoção de uma política mais gradualista em que os bancos centrais alongam seus horizontes e buscam atingir a meta de inflação mais à frente, no futuro. O gradualismo adotado - ou a flexibilidade implícita - pode ser explicado pelas preocupações dos bancos centrais com a estabilidade do produto e do emprego, com a volatilidade da taxa de câmbio, com a trajetória da taxa de juros e com as incertezas acerca do real estado da economia e dos modelos que orientam as decisões de políticas econômicas.

Flexible Inflation Forecast Targeting pode ser entendido como um regime que combina compromisso com flexibilidade, isto é, um regime de constrained discretion. Sob Flexible Inflation Forecast Targeting, os bancos centrais não seguem simples instruções mecânicas operacionais, Nas palavras de Bernanke (2003):

Under constrained discretion, the central bank is free to do its best to stabilize output and employment in the face of short-run disturbances, with the appropriate caution born of our imperfect knowledge of the economy and of the effects of policy (this is the "discretion" part of constrained discretion). However, a crucial proviso is that, in conducting stabilization policy, the central bank must also maintain a strong commitment to keeping inflation - and, hence, public expectations of inflation - firmly under control (the 'constrained' part of constrained discretion).

Contudo, ainda assim, deve ser ressaltado que nessa estratégia o principal instrumento de política monetária utilizado é a manipulação da taxa básica de juros. Nesse sentido, vale observar que, de um modo geral, manipulações na taxa básica de juros implicam mudanças no grau de liquidez da economia, com efeitos importantes sobre o financiamento de planos de investimento em ativos fixos e sobre o grau de preferência pela liquidez, que também, por sua vez, traz impactos sobre as decisões de investimento. Elevadas taxas de juros competem com as diferentes taxas de retorno de investimentos em ativos fixos, induzindo firmas a alocarem seus recursos em ativos mais líquidos. Assim, a despeito de uma taxa de inflação baixa, o comprometimento de recursos por longo período de tempo pode 
ser inibido por um patamar de taxa de juros muito elevado relativamente. Baixos níveis de investimento, por longos períodos de tempo, resultado de uma alta preferência pela liquidez influenciada em parte por elevadas taxas de juros, levam a uma redução no potencial de crescimento da economia. Essa redução faz com que breves períodos de aquecimento reduzam rapidamente o hiato do produto, provocando uma reação da política monetária que compromete ainda mais o potencial de crescimento.

\subsection{Políticas de metas de inflação estritas}

É importante ressaltar que bancos centrais que adotaram metas para a inflação não necessariamente fizeram isso da mesma maneira, ou seja, se utilizando do mesmo desenho institucional, da mesma estrutura de governança e da mesma forma de conduzir a política monetária. Como Mishkin e SchmidtHebbel (2002, p. 175) apontam: "inflation targeters vary widely with regard to implementation features, including the target price index, target width, target horizon, escape clauses, accountability of target misses, goal independence, and overall transparency and accountability of the conduct of policy".

Características como a urgência em fazer tanto a inflação observada quanto a expectativa de inflação convergirem para a meta, e os pesos conferidos às flutuações do emprego e do produto e à volatilidade da taxa de câmbio e da taxa de juros, em grande medida, definem se o regime de metas de inflação é mais flexível ou mais estrito. Assim, a literatura de metas de inflação identifica um arcabouço institucional de combate à inflação denominado strict inflation targeting. Por esse esquema, os bancos centrais somente se preocupam em atingir a meta de inflação, atribuindo peso zero a qualquer variabilidade do produto ou do emprego. Assim, quando a inflação ou as expectativas de inflação se desviam da meta de inflação, o banco central tenta fazer convergir a inflação e as expectativas de inflação de volta para a meta o mais rápido possível, o que requer mudanças consideráveis no principal instrumento de política monetária (a taxa de juros).

A ressalva que o trabalho se encarrega de fazer é em relação à forma de condução da política monetária pelo arcabouço de metas para a inflação, a qual subutiliza seu principal instrumento e outros instrumentos de política econômica. Nesse sentido a política de metas de inflação por um enfoque mais estrito busca a obtenção de um único resultado, qual seja a manutenção da inflação em um patamar baixo e estável, conferindo pouca ou quase nenhuma atenção aos resultados reais que se observam na economia. Na medida em que o arcabouço institucional e de condução da política monetária mais se aproxima do desenho institucional e de orientação compatível aos de regras estritas ou, especificamente, 
ao de strict inflation targeting, mais o potencial de crescimento da economia será afetado no longo prazo. ${ }^{11}$

\subsection{Política de metas de inflação e a visão pós-keynesiana}

Sob a hipótese da não neutralidade da moeda, a política monetária é eficaz em alterar tanto variáveis nominais quanto variáveis reais. ${ }^{12}$ Nesse sentido, entende-se a política monetária como desempenhando o papel de estabilização de variáveis nominais e estimulando emprego e produto, criando um ambiente propício para as decisões de investimento na economia.

De forma semelhante à visão convencional, o canal de expectativas é tido como um dos mais importantes para a atuação da política monetária, ${ }^{13}$ ou seja, na visão pós-keynesiana, a política monetária também exerce o papel de orientar expectativas. Porém, conforme apontam Carvalho et al. (2000, p. 171), "a eficácia da política monetária não depende exclusivamente da utilização dos seus instrumentos, mas é função, fundamentalmente, das avaliações sobre contextos futuros feitas pelos agentes econômicos". Assim, essas avaliações deverão levar em conta o crescimento potencial futuro da economia, variável determinante na alocação de recursos reais e financeiros de longo prazo pelos agentes econômicos.

Quanto mais rapidamente a autoridade monetária for bem-sucedida em instaurar um ambiente estável de preços, reduzindo tanto a variabilidade da inflação quanto a própria taxa, supõe-se que as condições ideais que levarão a um processo de crescimento econômico desejado e sustentável, com reduzida variabilidade do produto, estarão criadas. Contudo, podemos argumentar que sobre a hipótese de existir capacidade ociosa, a utilização de uma regra de manipulação da taxa de juros - como, por exemplo, a de Taylor (1993) - sob o arcabouço de strict inflation targeting, embora seja capaz de proporcionar a convergência das

(11) Além da crítica específica sendo elaborada pelo trabalho, o regime de metas de inflação, embora apresente uma série de vantagens - como já mencionado - apresenta, também, uma série de desvantagens, como aponta Mishkin (2007, p. 273): “Critics of inflation targeting have noted seven major disadvantages of this monetary policy strategy. Four of those disadvantages (that inflation targeting is too rigid, that it allows too much discretion, that it has the potential to increase output instability, and that it will lower economic growth) have been discussed in Mishkin (1999) and Bernanke et al. (1999) and are in reality not serious objection to a properly designed inflation-targeting strategy (...). The fifth disadvantage, that inflation targeting can only produce weak central-bank accountability because inflation is hard to control and because there are long lags from the monetary-policy instruments to the inflation outcomes, is an especially serious one for emerging-market countries. The sixth and the seventh disadvantages, that inflation targeting cannot prevent fiscal dominance, and that the exchange-rate flexibility required by inflation targeting might cause financial instability, are also very relevant in the emerging-market-country context".

(12) A política monetária que tem como objetivo estimular o crescimento econômico deve induzir os agentes a trocarem liquidez por iliquidez, assim como a trocarem rendimentos de juros por lucros.

(13) Para maiores detalhes acerca dos mecanismos de transmissão monetária, ver De Mendonça (2001), Berk (1998), Mishkin (1995) e Taylor (1995). 
expectativas de inflação e da própria inflação para a meta, pode ser responsável por gerar uma enorme volatilidade no instrumento de política monetária e, assim, induzir a economia a conviver com constantes taxas de crescimento abaixo daquelas desejadas pela sociedade, devido ao ambiente desfavorável criado para as decisões de investimento em ativos fixos. Ou seja, a política de metas de inflação estrita compromete o crescimento potencial da economia ao disciplinar os agentes econômicos a uma política de combate a qualquer tipo inflação por meio de manipulações da taxa básica de juros orientada pelas oscilações do hiato do produto e pelos desvios da inflação e das expectativas de inflação em relação à meta. Mesmo o regime de metas de inflação flexível, com menor volatilidade no instrumento de política monetária, pode ter o efeito de deprimir o potencial de crescimento da economia ao limitar os instrumentos de combate à inflação à manipulação da taxa de juros.

Uma consequência da adoção do strict inflation targeting a ser destacada é se transformar em uma potencial ameaça à própria autoridade monetária, criando o que se pode denominar de uma "armadilha de credibilidade". ${ }^{14}$ Como destacou Truman (2003, p. 3): "rigid frameworks may promise quick results, but they involve higher risk, especially in the context of a volatile global economic and financial environment, as Argentina, Brazil, and Turkey have recently learned".

Uma contribuição do pensamento pós-keynesiano ao debate sobre a eficácia da política monetária é buscar entender por quais mecanismos a política de manipulação da taxa de juros e, consequentemente, de controle da demanda agregada, afeta o comportamento dos preços em uma economia monetária. A recomendação de uma estratégia de conduta como a abordagem de strict inflation targeting, ou, por exemplo, como a regra de Taylor, pode ser considerada como limitada, sendo sua confiança questionável (Kozicki, 1999, para o caso da regra de Taylor), pois não leva em conta os elementos determinantes e as estratégias estabelecidas pelas firmas para o processo de formação de preços.

Assim, para avançarmos nessa discussão, é importante entender como preços são formados em economias de mercado. A política monetária, para ser considerada eficaz, deveria operar como coordenador de expectativas sobre o crescimento da economia, ou seja, influindo positivamente na formação de expectativas de longo prazo, que por sua vez afetam de maneira significativa a taxa de investimento produtivo.

(14) A credibilidade da política monetária não deve ser analisada somente como sendo capaz de promover a estabilidade da inflação. Pelo fato de ser capaz também de afetar o lado real, sua constante utilização pode levar a perda de credibilidade quando necessária para estimular a economia por meio do canal das expectativas, quando a inflação já estiver baixa e estável. 
Gabriel Caldas Montes / Carmem Aparecida Feijó

\section{Teoria dos preços pós-keynesiana}

$\mathrm{Na}$ abordagem pós-keynesiana, o papel que os preços exercem em economias de mercado e as alterações que neles se verificam vão além do mecanismo de ajuste entre oferta e demanda. Os movimentos nos preços resultam "de um processo de arbitragem coletiva sobre a distribuição de uma produção dada, onde o elemento dinâmico básico é a mutabilidade dos desejos dos consumidores individuais no gozo de sua liberdade" (Kandir, 1989, p. 26). E o autor ainda ressalta que "o processo de formação dos preços constitui, antes de mais nada, uma dimensão do processo de valorização dos capitais” (op. cit., p. 87).

Autores pós-keynesianos ${ }^{15}$ entendem que o processo de formação dos preços embute uma decisão das firmas quanto a sua estratégia de crescer considerando aspectos relacionados à percepção dos empresários quanto ao comportamento futuro dos custos de produção e financiamento, da demanda e da concorrência. ${ }^{16}$ Conforme aponta Kandir (op. cit., p. 88), "os processos de decisão de preços, mark ups desejados, quantidades produzidas, investimento e padrão de financiamento não são isolados. Ao contrário, constituem várias dimensões de um único processo de definição da estratégia de acumulação dos capitais particulares". Assim, as decisões de formação de preços não podem ser separadas nem do planejamento do investimento, nem do conflito distributivo entre trabalhadores e capitalistas (Eichner, 1976).

\subsection{Formação dos preços em economias de mercado}

Os objetivos de crescimento estabelecidos pelas firmas nos vários mercados em que operam são determinantes para explicar os movimentos que se observam nos preços. Ou seja, os preços são determinados levando em conta as estratégias estabelecidas para que seus objetivos de longo prazo sejam alcançados. Nesse sentido, tanto o poder de formar preço da firma é enfatizado como, também, o uso desse poder, de modo a atender os interesses de crescimento e sobrevivência, no longo prazo. O mark up é variável estratégica que se modifica tanto por influência do mercado, quanto por decisões tomadas pelas firmas para atingirem seus objetivos, considerando as expectativas de evolução do contexto macroeconômico.

(15) Por exemplo, Minsky (1986); Eichner (1973, 1976, 1985); Davidson (1978); Shapiro (1981); Shapiro e Sawyer (2003); Kenyon (1979); Harcourt e Kenyon (1976); Wood (1975); Kandir (1989); Arestis e Milberg (1993-1994); Feijó (1993a, 1993b); Nell (1992), dentre outros.

(16) A abordagem pós-keynesiana segue as considerações apresentadas por Penrose (1959) acerca dos objetivos estabelecidos pela firma e sua influência sobre a dinâmica das economias capitalistas. As firmas, ao estabelecerem a busca por um crescimento contínuo e acelerado de sua estrutura de capital, como principal objetivo, estariam atuando de forma determinante para o processo dinâmico de crescimento e desenvolvimento de uma economia capitalista. 
Em alguns momentos, por exemplo, por mais que a firma possa se encontrar em uma situação com graus de liberdade suficientes para promover aumentos de preços, legitimados por pressões da demanda, sua decisão pode ser por não fazê-lo caso os resultados não sejam compatíveis com seus objetivos de longo prazo. ${ }^{17}$ A firma poderia estar, com essa atitude, aumentando lucros em um primeiro instante, contudo, dependendo do grau de concorrência, poderia vir a perder fatias de mercado para firmas concorrentes.

Nesse sentido, as firmas, por meio de suas estratégias de formação de preços, são capazes de desenvolver, expandir e proteger seus mercados, alterando, assim, sua lucratividade e seu grau de competitividade. O processo de crescimento da firma encontra-se tanto subordinado a sua lucratividade quanto ao nível de competitividade que possui. Como as políticas de preços assumidas pelas firmas são capazes de afetar tanto a sua lucratividade quanto a sua competitividade, os preços acabam por refletir os interesses das firmas em vez de somente as condições das indústrias ou dos mercados em que estejam inseridas. A política monetária, ao influir no ritmo de expansão da economia, também estará afetando os prognósticos da firma quanto às suas estratégias de crescimento.

A política de determinação dos preços é um dos componentes na geração de fundos necessários ao financiamento das despesas planejadas de investimento das firmas, logo existe uma forte relação estabelecida entre preços, lucros e investimentos. Eichner (1985), assim como Kalecki ${ }^{18}$ (1952), se dá conta de que os lucros representam a fonte principal de fundos utilizados para financiar os investimentos e para alavancar recursos no mercado financeiro. Portanto, os preços estabelecidos pelas firmas desempenham um papel fundamental no processo de crescimento de cada uma delas. ${ }^{19}$

(17) Shapiro e Sawyer (2003, p. 358) afirmam que: "Prices do not necessarily change with the demand for products just as they do not necessarily change with the costs, and they do not so for the same reason: the price changes may not be in the interests of the firm".

(18) De acordo com Kalecki (1952): "O consumo dos capitalistas em um certo período resulta de suas decisões baseadas nos lucros do passado". Ele estabeleceu uma relação biunívoca entre lucros e investimento. Por um lado, atribuiu aos lucros a importância de serem a fonte principal de fundos utilizados para financiar os investimentos; nesse sentido, nada seria mais importante no processo de determinação dos lucros do que os preços que as firmas são capazes de cobrar. Sendo assim, os preços estabelecidos pelas firmas desempenham um papel central para o processo de crescimento e distribuição do produto e da riqueza. Por outro lado, seu modelo mostra que os lucros são determinados pelo investimento, mais precisamente pelas decisões passadas de investir.

(19) Eichner (1985, p. 123) sugere o seguinte: "All that is necessary is that, through some combination of market power and current levels of demand, firms be able to establish the margins above costs that will bring them sufficient net cash inflow, or savings, to finance their planned investment". Contudo, ele atenta para o fato da impossibilidade de total geração de fundos internamente e, nesse sentido, para o papel que venha a desempenhar o sistema bancário no fomento dos planos de investimento: "Even if all the required funds cannot be generated internally, as long as the banking system is willing to extend credit the results will be the same: business firms will be able to obtain the real resources they need to carry out their investment plans". 
Como decorrência desse raciocínio, o processo de determinação do mark up não deve ser visto como simplesmente explicado por condições de curto prazo associadas à demanda, como sugerem os modelos de formação de preços tradicionais, mas sim, e também, pelas necessidades de financiamento dos empreendimentos de longo prazo (Eichner, 1985, pp. 165-166). Essas necessidades são definidas em função da percepção que os empresários têm quanto às condições e oportunidades de crescimento, fazendo com que cada firma escolha uma trajetória própria a ser seguida. Ou seja, expectativas de ganhos de longo prazo são determinantes para a fixação do mark up no curto prazo.

Assim, para os pós-keynesianos, seguindo Penrose (1959), a firma busca maximizar crescimento no longo prazo e não lucro a curto prazo. Como apontam Shapiro e Sawyer (2003, p. 264),

although profit is the overriding objective of the firm - it could neither survive nor grow without it - its price do not maximize profit. And this is the case not only because the firm cannot foresee all the consequences of its actions and thus cannot know the price that will maximize profit. It is also because profit maximization assumes given cost and demand conditions, and neither the cost of products nor the demand for them is taken as given in the product pricing of the firm.

Em resumo, os fins específicos do empreendimento capitalista afetam fortemente o processo de formação de preços das firmas, tanto quanto afetam as dimensões temporais da estrutura desse processo. Embora a firma necessite gerar internamente os fundos suficientes que abasteçam seu processo de crescimento, deve estar atenta, também, à necessidade de assegurar mercados suficientemente extensos que absorvam o potencial produtivo de seu aparato instalado. As margens de lucro, portanto, podem se alterar ao longo do tempo de acordo com as necessidades de serem assegurados os mercados, assim como de serem aceleradas as taxas de crescimento da firma. Por exemplo, a demanda por fundos que financie o processo de acumulação exerce pressão altista sobre a margem de lucro da firma e sobre o mark up; ao passo que um acirramento no grau de competitividade entre as firmas em um mesmo mercado pressiona a margem de lucro a se reduzir de modo a manter a participação da firma no mercado.

\subsection{Preços e financiamento}

Minsky (1986) aponta que a teoria dos preços neoclássica é limitada em explicar como os preços relativos se ajustam de modo a fazer com que mercados se equilibrem, pois são ignoradas as relações legítimas entre preços de ativos financeiros e de capital que devem ser satisfeitas de maneira a tornar o funcionamento da economia mais coerente. Adverte que, de acordo com a abordagem neoclássica, a única função dos preços é servir como um mecanismo 
determinante para o processo de alocação de recursos e de regulação da produção. Nesse sentido, argumenta que

if the economy is to be coherent, prices must accomplish not only the resource allocation and output-rationing functions but also assure that (1) a surplus is generated, (2) incomes are imputed to capital assets (i.e., profits), (3) the market prices of capital assets are consistent with the current production costs of outputs that become capital assets, and (4) obligation on business debts can be fulfilled (Minsky, 1986, p. 141).

O esquema acerca dos determinantes do processo de formação de preços apresentado por Minsky considera que o sistema de preços deve estar voltado para gerar os lucros (ou cash flows) suficientes que liberem recursos para o processo de financiamento dos investimentos. As firmas devem, portanto, inserir em seus preços de oferta um montante que além de exceder os seus custos possa, também, gerar os fundos suficientes que sustentem ou valorizem os seus ativos de capital. Os preços, nesse sentido, não podem ser tratados como funções do processo de alocação de recursos e distribuição de renda somente; devem estar relacionados, também, à necessidade de geração de fundos que torne possível o processo de acumulação de capital, além de viabilizarem o pagamento de dívidas, induzirem e parcialmente financiarem os investimentos e possibilitarem que novas obrigações financeiras sejam aceitas (Minsky, 1986, p. 142).

$\mathrm{O}$ processo de formação de preços encontra-se, portanto, associado à habilidade, à capacidade e à possibilidade do empreendedor de aumentar a sua participação no processo de formação, distribuição e acumulação da riqueza. $\mathrm{Ou}$ seja, o processo encontra-se vinculado com o desejo de serem obtidos lucros cada vez maiores, pois esses traduziriam a busca pela acumulação crescente e acelerada da riqueza. A ideia do empreendedor que busca auferir lucros cada vez maiores é, portanto, que esses, quando gerados, sejam suficientes para, basicamente: 1) auxiliar no processo de geração de fundos necessários que possibilitem dar continuidade ao processo de acumulação de capital e geração de riqueza; e 2) manter ou aumentar a participação da firma no processo de produção e absorção das riquezas geradas.

\subsection{Comportamento do mark up e variações nos custos de produção}

Considerando que os preços são formados de maneira estratégica por meio de uma regra de mark up sobre os custos, dado um nível de produção considerado padrão (Davidson, 1978), Kenyon (1979, p. 39) propõe uma sequência lógica para a determinação do mark up. Primeiro, a firma traça os planos futuros de 
investimento $^{20}$ com base na relação entre a taxa observada de utilização da capacidade instalada e alguma taxa desejada de utilização - essa taxa desejada será tal que a firma esteja apta a atender a um aumento repentino da demanda pelo seu produto; em seguida, a firma irá escolher o mark up que irá permitir reter os lucros necessários ao cumprimento de suas obrigações e atendimento de seus objetivos. A firma irá manter ou alterar seu preço de acordo com as condições de demanda indicadas pela utilização da capacidade instalada e de acordo com as oscilações observadas nos custos em torno de um nível considerado normal.

Por esse raciocínio, embora formados considerando os custos, os preços não são determinados exclusivamente por eles. Não existe um mecanismo de transmissão automática de variações nos custos para os preços, isto é, os preços dependem do mark up (uma decisão estratégica), assim como dos custos. Com isso, quando os custos se alteram, não necessariamente os preços se alteram, o mark up sobre os custos pode se alterar em vez dos preços.

Os preços irão sofrer alterações se estas servirem ou se esperar que sirvam aos interesses da firma. Embora um aumento nos custos - mantido o preço fixo reduza a margem de lucro, um aumento do preço de modo a compensar essa perda pode não se reverter em um negócio rentável, pois o aumento do preço pode vir a afetar as vendas do produto. $\mathrm{O}$ aumento do preço pode reduzir a competitividade do produto da firma, sendo verificada uma alteração dos preços relativos, segundo Kandir (1989, p. 88): "A concorrência, através das estruturas de mercado, estabelece o espaço de realização das arbitragens particulares dos preços”.

A manutenção do mark up por meio do aumento do preço, quando verificada uma elevação dos custos, pode se configurar como uma estratégia equivocada, caso as firmas concorrentes possuam estruturas de custos diferenciadas e não tenham sido afetadas de maneira semelhante. Uma firma operando em uma estrutura com oferta de produtos diferenciados, contudo substitutos próximos, ao adotar a estratégia de elevação do preço, caso seus custos tenham aumentado, pode acabar experimentando uma queda acentuada na receita de vendas e, portanto, uma queda na geração de fundos que financiarão novos investimentos. Ou seja, essa decisão de curto prazo a ser tomada acerca do preço pode, de fato, afetar o alcance dos objetivos de longo prazo estabelecidos pela firma. Nesse sentido, a manutenção do preço do produto pode ser necessária para que sejam preservadas suas vendas (ou seu market-share).

Por outro lado, se a pressão de custo é acompanhada por uma retração da demanda devido a uma política monetária recessiva, obviamente os efeitos sobre a

(20) Os planos de investimento levarão em conta as projeções que a firma faz para o futuro crescimento da demanda de mercado e as estimativas quanto à lucratividade de outros projetos de investimento alternativos (Kenyon, 1979). 
acumulação interna de fundos e sobre o produto serão adversos tanto na primeira situação, quando firmas reduzem o mark up, como na segunda, quando firmas mantêm o mark up diante de um aumento de custos de produção. No primeiro caso, os prognósticos de receita devem se reduzir pela contração da demanda. Assim, no contexto de uma inflação de custos, outros instrumentos de combate à inflação devem ser utilizados a fim de não comprometer o crescimento econômico ao longo do tempo.

Num regime de metas de inflação flexível, pressões de custos podem ser consideradas no arcabouço do regime, por exemplo, por meio do controle sobre o núcleo da inflação ou sobre o tempo de obtenção da meta. A opção pelo arranjo institucional mais flexível deve implicar menor ônus sobre o produto no processo de combate à alta de preços. Deve-se observar que, quanto mais homogênea e mais competitiva for a estrutura produtiva, menor deverá ser o custo em termos do produto no combate à inflação, mesmo não se considerando instrumentos alternativos de política econômica que atuem especificamente sobre a causa da inflação. No entanto, como já enfatizado, o uso da manipulação da taxa de juros como um único instrumento de combate à inflação traz consequências sobre a formação das expectativas dos agentes produtivos em relação aos cenários futuros de crescimento da economia, reduzindo o potencial de crescimento econômico a longo prazo.

Por outro lado, sob uma estratégia de metas de inflação estrita, maior o ônus da busca de estabilidade de preços sobre o produto e, consequentemente, sobre o potencial de crescimento futuro da economia.

Em suma, na visão pós-keynesiana, o processo inflacionário resulta de um conflito distributivo. Nesse sentido, agentes econômicos formam suas expectativas e implementam suas estratégias de preço com base em manter ou ampliar seus interesses participativos na geração de riqueza econômica. Como, sob o regime de metas de inflação, as expectativas de inflação afetam a condução da política monetária, os agentes, com intuito de influenciar a política monetária e, assim, promover redistribuições de renda em seus próprios benefícios, formam expectativas de modo a exercerem influência sobre a autoridade monetária e, com isso, atenderem a seus interesses. Não necessariamente a soma desses interesses leva a um aumento do produto potencial da economia.

\subsection{Comportamento dos preços e variações na demanda}

Da mesma forma que variações no custo de produção não afetam a determinação de preço diretamente, aumentos na demanda afetarão os preços dependendo do grau de utilização dos fatores e do grau de concorrência dos mercados. Em mercados onde a firma tem vantagens competitivas, aumentos de 
demanda podem significar aumentos de preços, mesmo com capacidade de produção disponível. Em mercados competitivos, com ociosidade, aumentos na demanda podem ocorrer e ainda assim os preços, de um modo geral, permanecerem estáveis.

Como vimos, empresas decidem o quanto produzir e o quanto cobrar pelo produto em função de suas expectativas de curto prazo e de seus objetivos de longo prazo. Nesse contexto, a política monetária de controle da inflação deve considerar que usar somente um instrumento, como a taxa de juros, pode trazer consequências adversas sobre a produção, o emprego e a alocação de recursos acumulados. Considerando que o objetivo da firma é crescer, uma política monetária continuamente recessiva com a manutenção de elevadas taxas de juros pode limitar o potencial de crescimento das firmas. Em tal circunstância, considerando que a política de preços da firma é parte de sua estratégia de acumulação de fundos, a melhor política a ser seguida pode ser a alocação de recursos acumulados em ativos mais líquidos do que o investimento em ampliação de capacidade. A longo prazo o crescimento da economia é comprometido pelo baixo investimento em formação de capital, limitando o potencial de crescimento da economia. Advoga-se, portanto, pela existência de uma relação biunívoca entre a percepção do contexto macroeconômico e as decisões das firmas, isto é, tanto o ambiente macroeconômico afeta as decisões das firmas quanto as decisões das firmas são capazes de afetar o contexto macroeconômico.

Três situações podem ser discutidas, como mostra o Quadro 1, para se avaliar a influência do produto demandado sobre o comportamento dos preços, considerando a análise acerca do grau de utilização da capacidade instalada para explicar os impactos das pressões de demanda sobre a inflação.

Se a economia estiver em uma situação na qual o produto observado é menor do que o produto crítico $^{21}$ (primeiro caso), então, uma elevação da demanda agregada não irá se traduzir em elevação da inflação. Se a economia estiver em uma situação em que o produto observado se encontra em um nível entre o produto crítico e o produto de pleno emprego (segundo caso), então, uma elevação da demanda agregada, embora estimule o produto, poderá também elevar a inflação. Se o produto observado equivale ao produto de pleno emprego (terceiro caso), isto é, existe plena utilização da capacidade instalada, então, caso a demanda agregada aumente, a inflação também irá se elevar.

(21) O produto crítico é uma situação em que o nível do produto que se observa na economia é resultado de uma elevada utilização da capacidade instalada, ou seja, um nível de produto que se encontra muito próximo ao produto de pleno emprego. Uma economia operando no nível do produto crítico, ou além desse, pode vir a observar um aumento generalizado dos preços, caso a demanda da economia esteja se elevando. 
Decisão de preços em economias monetárias e metas de inflação: a difícil conciliação entre crescimento ...

Quadro 1

Pressão inflacionária de demanda e efeito sobre a formação de expectativas de preço e de produto

\begin{tabular}{|c|c|c|}
\hline $\begin{array}{c}\text { Situação da demanda } \\
\text { agregada em relação ao } \\
\text { produto de pleno emprego }\end{array}$ & $\begin{array}{l}\text { Regime de } \\
\text { metas de } \\
\text { inflação }\end{array}$ & $\begin{array}{l}\text { Efeito sobre a formação de expectativas de } \\
\text { inflação e produto }\end{array}$ \\
\hline \multirow[t]{2}{*}{$\begin{array}{l}\text { Produto observado é menor } \\
\text { do que o produto de pleno } \\
\text { emprego e menor do que o } \\
\text { produto crítico }\end{array}$} & Mais Flexível & $\begin{array}{l}\text { Economia pode iniciar ciclo de crescimento com } \\
\text { inflação sob controle. A sustentabilidade do } \\
\text { crescimento irá depender do grau de confiança nas } \\
\text { expectativas favoráveis de crescimento para } \\
\text { induzir firmas a crescentemente alocarem recursos } \\
\text { em ativos fixos }\end{array}$ \\
\hline & Mais Estrito & $\begin{array}{l}\text { Rigidez no controle da inflação retarda/inibe } \\
\text { retomada do crescimento }\end{array}$ \\
\hline \multirow{2}{*}{$\begin{array}{l}\text { Produto observado próximo } \\
\text { do produto de pleno } \\
\text { emprego e maior do que o } \\
\text { produto crítico }\end{array}$} & Mais Flexível & $\begin{array}{l}\text { Economia pode manter crescimento, porém com } \\
\text { ligeira aceleração da inflação. Outros instrumentos } \\
\text { de política econômica devem ser utilizados para } \\
\text { controlar a pressão sobre preços (apresenta menor } \\
\text { volatilidade da taxa de juros) }\end{array}$ \\
\hline & Mais Estrito & $\begin{array}{l}\text { Crescimento da economia é interrompido em prol } \\
\text { da estabilidade das expectativas de inflação e da } \\
\text { própria inflação (apresenta maior volatilidade da } \\
\text { taxa de juros) }\end{array}$ \\
\hline \multirow{2}{*}{ Produto de pleno emprego } & Mais Flexível & $\begin{array}{l}\text { Após uma aceleração da inflação e das } \\
\text { expectativas de inflação, essas irão convergir de } \\
\text { maneira mais lenta para a meta, prejudicando } \\
\text { menos o produto e o emprego (ainda assim } \\
\text { apresenta uma menor volatilidade da taxa de juros) }\end{array}$ \\
\hline & Mais Estrito & $\begin{array}{l}\text { Eficaz no combate à inflação e sérias } \\
\text { consequências sobre produto e emprego devido à } \\
\text { urgência em fazer a inflação e suas expectativas } \\
\text { convergirem para a meta (fortes modificações na } \\
\text { taxa de juros) }\end{array}$ \\
\hline
\end{tabular}

O primeiro caso indica que, em uma situação na qual o nível de produto da economia é menor do que o nível de produto crítico, quando verificada uma variação positiva do produto demandado, essa não irá se reverter em um aumento da inflação, contudo, uma variação negativa do produto demandado irá resultar em uma redução da inflação, ou levar a uma deflação Esse comportamento assimétrico pode ser explicado pelo fato de as firmas estarem preocupadas em conquistar maiores fatias de mercado; assim, quando estimuladas a produzirem mais devido a um aumento da demanda e dado que operam com elevada capacidade ociosa, não repassarão as pressões de demanda para os preços por uma 
questão estratégica. Por outro lado, quando a demanda da economia se reduz e a produção já se encontra realizada, uma maneira de as firmas reduzirem os estoques que se formam indesejadamente é por meio da redução dos preços, o que se reverte em uma diminuição da inflação. A persistência de um baixo nível de demanda agregada pode levar à deflação, ou seja, uma situação em que a queda continuada nos preços desestimula a produção. Nesse caso, a política monetária deveria ser expansiva, em combinação com outras políticas de incentivo ao aumento da demanda agregada.

O segundo caso pode ser entendido como uma situação em que pressões de demanda podem ou não se reverter em aumentos da inflação. As firmas, nesse caso, quando observam aumentos da demanda, podem optar por não aumentarem os preços, tanto por uma questão estratégica quanto por acreditarem que policymakers irão atuar por meio de políticas econômicas de retração da demanda. No entanto, podem promover aumentos dos preços se estes não atrapalharem seus objetivos de longo prazo e/ou por acreditarem em seu poder de mercado. Nesse caso, a política monetária recessiva irá afetar de forma diferenciada os setores da economia, atingindo duramente aqueles mais competitivos. Outro aspecto negativo é a influência que tal política exerce sobre a percepção das firmas em termos de potencial de crescimento. A política monetária com adoção de regra de conduta desconsidera sua influência na capacidade de alavancar o potencial de crescimento da economia, ou seja, de ampliar a distância entre o produto crítico e o produto observado, por meio do deslocamento do nível de produto de pleno emprego para cima.

O terceiro caso representa uma situação em que o produto da economia equivale ao produto de pleno emprego. Sendo assim, enquanto o produto demandado estiver se elevando, as firmas, de maneira generalizada, dado que se encontram operando no potencial de sua capacidade instalada, responderão por meio de elevações dos preços. Nesse caso, a política de contenção de demanda deve ser aplicada para desacelerar a inflação.

\section{Considerações finais}

A política monetária é eficiente em controlar a inflação por meio de manipulações da taxa básica de juros, produzindo efeitos sobre a demanda agregada. Porém, o processo inflacionário nem sempre tem sua origem em um excesso de demanda agregada. Esse trabalho mostrou que, ao se reduzir a forma de combate à inflação a um único instrumento e de maneira estrita - como o caso de strict inflation targeting -, atingem-se outros aspectos da vida econômica que podem comprometer o potencial de crescimento da economia a longo prazo. Mesmo com uma política de metas de inflação flexível, o potencial de crescimento 
da economia pode ser reduzido na medida em que a política monetária reduz as expectativas dos agentes quanto ao crescimento futuro.

Os que defendem que os bancos centrais devem ser orientados a conduzir suas políticas monetárias de modo a promoverem única e exclusivamente a estabilidade dos preços por meio do mecanismo proposto pelo regime de strict inflation targeting avaliam o sucesso do regime com base somente nos desvios da taxa de inflação e das expectativas de inflação em relação à meta. Atribuem, assim, pequeno peso ou nenhuma consideração para os impactos sobre fatores reais ou outros objetivos de política econômica, não estando estes associados aos parâmetros que medem o sucesso do regime. O argumento favorável para a aplicação desse regime específico é o efeito capaz de causar sobre as expectativas de estabilização da inflação. Porém o aumento na previsibilidade na evolução dos preços não é suficiente para acelerar o processo de crescimento. A constante manipulação das taxas de juros leva a um aumento das incertezas que acaba afetando a preferência pela liquidez dos agentes econômicos. Num contexto onde a manutenção da meta implica manter a taxa de juros elevada e se alterando constantemente, a preferência pela liquidez (preferência por ativos mais líquidos) também será elevada, inibindo a alocação de recursos em ativos fixos com taxa de retorno não competitiva com as taxas de juros praticadas.

Reconhecer que a causa da inflação nem sempre tem origem no excesso de demanda implica dizer que economias que estejam operando abaixo do pleno emprego - com baixa utilização da capacidade instalada - quando convivendo com inflação indesejada, esta última teria sua explicação pelo lado da oferta. Nesse sentido, o trabalho investigou o processo de formação de preços em uma perspectiva pós-keynesiana e, também, como uma estratégia de política monetária rígida, embora seja capaz de atingir certo objetivo (inflação baixa e estável), é também capaz de ser nociva em termos de desempenho econômico em geral. A relação entre a decisão de preço da firma e o contexto macroeconômico pode ser entendida da seguinte maneira: a política de fixação de mark up encontra-se associada ao processo de geração de fundos internos que viabilizarão planos de investimento e a alavancagem de recursos financeiros necessários para a realização dos planos que serão executados, conforme o estado de expectativas em relação ao futuro desempenho da economia. Dado que o contexto macroeconômico reflete o desempenho corrente da economia e este é afetado pela política monetária, trazendo consequências sobre o estado de expectativas, isso implica que, em última instância, a autoridade monetária por meio de suas políticas afeta o estado de expectativas dos agentes e, assim, suas decisões de 
curto e longo prazos - como as decisões de preços e alocação de recursos acumulados. ${ }^{22}$

Assim, a abordagem pós-keynesiana mostra que as decisões individuais tomadas pelas firmas acerca de seus preços, volume de produção, alocação de recursos nas esferas financeira e produtiva refletem, em última instância, a percepção sobre uma trajetória de crescimento que depende da avaliação do contexto corrente e futuro.

Como há uma diversidade de fatores responsáveis por desencadear o processo inflacionário, deve haver diferentes classificações para as suas causas e, de acordo com o diagnóstico emitido acerca do processo inflacionário, devem ser escolhidos os instrumentos ou uma combinação de instrumentos a serem utilizados no seu combate.

A política monetária, ao atuar por meio de uma estratégia rígida, desconsidera: 1) o processo de formação de preços como resultando do conflito distributivo entre grupos de agentes econômicos com interesses específicos, o que equivale a dizer que as regras afetam de forma diferente grupos econômicos com distintas inserções na estrutura produtiva; 2) os impactos diferenciados da política de juros conforme a estrutura de custos das empresas, o que provoca diferentes reações das firmas; e 3) as consequências para o processo de acumulação de fundos das empresas. Logo, a adoção de uma estratégia do tipo strict inflation targeting cria, de fato, uma armadilha de credibilidade para a política monetária futura, pois para manter uma dada reputação a autoridade monetária deve manter suas regras de conduta que não priorizam o crescimento.

Embora o processo inflacionário seja comumente tratado como um problema passível de explicação teórica no âmbito estritamente macroeconômico, sua compreensão requer um entendimento muito mais abrangente sobre o processo de formação de preços por parte das firmas, pois o nível geral de preços não passa de uma abstração que agrega os mais diversos preços. Nesse sentido, uma abordagem preliminar microeconômica faz-se necessária, embora não seja condição suficiente para a elaboração de uma análise teórica acerca do processo inflacionário e como esse processo deva ser combatido quando situado em um patamar indesejável. Isto é, compreender teoricamente o processo inflacionário e sua dinâmica, assim como propor políticas de combate à inflação, requer uma análise integrada entre as esferas micro e macroeconômica.

(22) Para maiores detalhes acerca da influência da autoridade monetária sobre o estado de expectativas e sobre as decisões dos agentes econômicos, ver Montes e Feijó (2007) e Montes (2007). 


\section{Bibliografia}

ANGERIZ, A.; ARESTIS, P. Has inflation targeting had any impact on inflation?" Journal of Post Keynesian Economics, Summer, v. 28, n. 4, p. 559, 2006.

ARESTIS, P.; MILBERG, W. Degree of monopoly, pricing, and flexible exchange rates. Journal of Post Keynesian Economics, Winter, v. 16, n. 2, p. 167, 1993-1994.

BATINI, N.; MARTIN, B.; SALMON, C. Monetary policy and uncertainty. Bank of England Quarterly Bulletin, May, 1999.

BERK, J. M. Monetary transmission: what do we know and how can we use it? $B N L$ Quarterly Review, n. 205, 1998.

BERNANKE, B. S. A Perspective on inflation targeting. At the Annual Washington Policy Conference of the National Association of Business Economists, Washington, D.C., March 25, 2003.

; LAUBACH, T.; MISHKIN, F. S.; POSEN, A. Inflation targeting: lessons from the international experience. Princeton University Press, 1999.

CARVALHO, F. C. Políticas econômicas para economias monetárias. In: LIMA, G. T.; SICSÚ, J.; DE PAULA, L. F. (Org). Macroeconomia moderna: Keynes e a economia contemporânea. Rio de Janeiro: Campus, 1999.

Campus, 2000.

et al. Economia monetária e financeira: teoria e prática. Rio de Janeiro:

DAVIDSON, P. Money and the real world. 2. ed. New York: Macmillan, 1978.

DE MENDONÇA, H. F. Mecanismos de transmissão monetária e a determinação da taxa de juros: uma aplicação da regra de Taylor ao caso brasileiro. Economia e Sociedade, Campinas, n. 16, p. 65-81, 2001.

DEQUECH, D. Expectations and confidence under uncertainty. Journal of Post Keynesian Economics, v. 21, n. 3, Spring, 1999a.

. Uncertainty, conventions and short-term expectations. Brazilian Journal of Political Economy (REP), v. 19, n. 3 (75), Jul./Sept. 1999 b.

DOW, S. C. Uncertainty and monetary policy. Oxford Economic Papers, n. 56, 2004.

ECB. Monetary policy-making under uncertainty. ECB Monthly Bulletin, Nov. 2001.

EICHNER, A. S. A theory of determination of the mark-up under oligopoly. The Economic Journal, London, v. 83, n. 332, p. 1184-1200, 1973.

The Megacorp and Oligopoly - micro foundations of macro dynamics. Cambridge: Cambridge University Press, 1976.

Toward a new economics: Essays in post-Keynesian and intuitionalist theory. Nova York: M. E. Sharpe, 1985.

FEIJÓ, C. A. A firma em um ambiente inflacionário. Análise Econômica, Porto Alegre, v. 11, n. 19 , p. 122-135, 1993a. 
Gabriel Caldas Montes / Carmem Aparecida Feijó

FEIJÓ, C. A. Decisões empresariais em uma economia monetária de produção: notas para uma teoria pós-keynesiana da firma. Revista de Economia Política, São Paulo, v. 13, n. 1, p. 82-100, $1993 \mathrm{~b}$.

HARCOURT, G. C.; KENYON, P. Pricing and the investment decision. Kyklos, v. 3, n. (3), p. 33-50, 1976.

KALECKI, M. Teoria da dinâmica econômica: ensaios sobre as mudanças cíclicas e a longo prazo da economia capitalista. In: Keynes/Kalecki. São Paulo: Abril Cultural, 1952. (Os Pensadores).

KANDIR, A. A dinâmica da inflação. São Paulo: Nobel, 1989.

KENYON, P. Pricing. In: EICHNER, A. S. (Org.). A guide to post-keynesian theory. White Plains, NY: M. E. Sharpe, 1979.

KOZICKI, S. How useful are Taylor rules for monetary policy? Economic Review (Federal Reserve Bank of Kansas City), Second quarter, 1999.

MINSKY, H. P. Stabilizing an unstable economy. New Haven: Yale University Press, 1986.

Induced investment and business cycles. Edward Elgar Publishing, 2004.

MISHKIN, F. S. Symposium on the monetary transmission mechanism. Journal of Economic Perspectives, v. 9, n. 4, Fall, 1995. Nov./Dec. 2000.

What should Central Banks do? Federal Reserve Bank of St. Louis Review, . Can inflation targeting work in emerging market countries? NBER Working Papers Series, 2004. (WP 10646). Disponível em: http://www.nber.org/papers/w10646.

. Monetary policy strategy. The MIT Press, 2007.

; SCHMIDT-HEBBEL, K. A decade of inflation targeting in the world: what do we know and what do we need to know. In: LOAYZA, Norman; SOTO, Raimundo (Ed.). Inflation targeting: design, performance, challenges. Central Bank of Chile, 2002.

MONTES, G. C. Metas de inflação em perspectiva: a influência do trinômio reputaçãocredibilidade-transparência sobre a economia. Revista de Economia Política, v. 28, n. 4 (112), p. 648-668, 2008.

; FEIJÓ, C. A. Reputação, credibilidade e transparência da autoridade monetária. Economia e Sociedade, Campinas, v. 16, n. 2, p. 151-170, 2007.

NELL, E. J. Demand, pricing and investment. In: MILBERG, Willian (Org.). The Megacorp \& Macrodynamics: essays in memory of Alfred Eichner. M. E. Sharpe, 1992.

OREIRO, J. L. C.; PASSOS, M. O. A governança da política monetária brasileira: análise e proposta de mudança. Indicadores Econômicos, FEE, Porto Alegre, v. 33, n. 1, p. 157$168,2005$.

PENROSE, E. (1959). The theory of the growth of the firm. $2^{\text {nd }}$. ed. Oxford: Basil Blackwell, 1980. 
SHAPIRO, N. Pricing and the growth of the firm. Journal of Post Keynesian Economics, v. IV, n. 1, Fall, 1981.

; SAWYER, M. Post Keynesian price theory. Journal of Post Keynesian Economics, v. 25, n. 3, p. 355, Spring, 2003.

SICSÚ, J. Políticas não-monetárias de controle da inflação: uma proposta pós-keynesiana. Revista Análise Econômica, ano 21, n. 39, jan./mar. 2003.

SVENSSON, L. Monetary policy and inflation targeting. NBER Reporter, Winter, 19971998.

. How should monetary policy be conducted in an era of price stability? NBER Working Paper, Oct. 1999.

TAYLOR, J. Discretion versus policy rules in practice. Carneige-Rochester Conference on Public Policy, 39, p. 195-214, 1993.

. The monetary transmission mechanism: an empirical framework. Journal of Economic Perspectives, v. 9, n. 4, Fall, 1995.

TRUMAN, E. M. Inflation targeting in the world economy. Washington, D.C: Institute for International Economics, 2003.

WOOD, A. A theory of profits. London: Cambridge University Press, 1975. 